Article

\title{
Online Speed Estimation Using Artificial Neural Network for Speed Sensorless Direct Torque Control of Induction Motor based on Constant V/F Control Technique
}

\author{
Narongrit Pimkumwong and Ming-Shyan Wang * \\ Department of Electrical Engineering, Southern Taiwan University of Science and Technology, No.1, \\ Nan-Tai Street, Yung Kang District, Tainan City 71005, Taiwan; p.narongrit@gmail.com \\ * Correspondence: mswang@stust.edu.tw; Tel.: +886-6-2533131 (ext. 3328)
}

Received: 9 August 2018; Accepted: 19 August 2018; Published: 20 August 2018

\begin{abstract}
This paper presents the speed estimator for speed sensorless direct torque control of a three-phase induction motor based on constant voltage per frequency $(\mathrm{V} / \mathrm{F})$ control technique, using artificial neural network (ANN). The estimated stator current equation is derived and rearranged consistent with the control algorithm and ANN structure. For the speed estimation, a weight in ANN, which relates to the speed, is adjusted by using Widrow-Hoff learning rule to minimize the sum of squared errors between the measured stator current and the estimated stator current from ANN output. The consequence of using this method leads to the ability of online speed estimation and simple ANN structure. The simulation and experimental results in high- and low-speed regions have confirmed the validity of the proposed speed estimation method.
\end{abstract}

Keywords: speed estimation; artificial neural network; direct torque control; induction motor drives

\section{Introduction}

The single biggest consumer of electricity in modern society comes from industrial and domestic electric motors. Three-phase induction motors (IMs) are widely used in industrial applications because they have simple structure, low cost, reliability, more efficiency, robustness and low maintenance. However, they are nonlinear and strongly coupled. For these reasons, several control methods have been developed. In recent years, the two most popular high performance control methods for IM drives are field-oriented control (FOC) and direct torque control (DTC) [1-3]. These control algorithms can decouple control between torque and flux and offer good dynamic and steady-state torque responses. DTC is more attractive than FOC in simplicity, less parameter sensitivity, quick torque response and effortless implementation complexity. Moreover, the coordinate transformation and the current regulators are not required [1]. However, for appropriate stator voltage selection, it uses nonlinear hysteresis comparators and look-up switching table that produce high torque and flux ripples and variable switching frequency cause noises, vibrations and increased losses $[4,5]$. To overcome these problems, DTC using space vector modulation (DTC-SVM), DTC with duty cycle control, model predictive torque control (MPTC), etc. have been introduced.

Direct torque control based on constant voltage per frequency $(\mathrm{V} / \mathrm{F})$ control technique (DTC-CVFC) [6,7] is a control method for control IM. The stator voltage magnitude and phase angle references for controlling the IM are generated based on constant V/F control principle by considering from torque and stator flux magnitude errors. In this control method, the current regulators are not required and the flux and torque are controlled independently. Its control scheme is simple and similar to the traditional DTC and DTC-SVM. The nonlinear hysteresis comparators and look-up 
switching table are replaced by the proportional-integral (PI) controllers and SVM technique when comparing with the traditional DTC. The coordinate transformation, which is used in DTC-SVM, is not required. As a result, the torque and flux ripples are reduced and the switching frequency is constant. However, the speed signal is required in this control algorithm. Speed signal is generally achieved in two ways: one is the direct measurement through speed sensors such as tachogenerators, optical rotary encoders and magnetic rotary encoders; the other is the software based state observers and estimators by other physical parameters known as speed sensorless.

The speed sensorless control of IM drives has attracted attention due to its advantages of reduction of hardware complexity and cost, eliminating of sensor cables, higher mechanical robustness, increasing the system reliability, lower maintenance requirements and cost, and ability of working in hostile environments. Several speed estimation methods for the speed sensorless IM drives have been proposed and investigated. They can be classified into two categories: machine model-based schemes and signal injection-based schemes [8-14].

Signal injection-based schemes use rotor slot harmonics, saturated, and leakage inductances for speed estimation by injecting high or low frequency signals. In [8-10], high frequency signal injection methods are introduced for speed estimation. A low frequency signal injection method for sensorless control of interior permanent magnet synchronous motor (IPMSM) drives is presented in [11]. These methods are insensitive to motor parameter variations and provide accurate speed estimation, especially at low speed [12]. However, they are very complicated to implement, strongly rely on motor designs and require special designs for specific motor drives [12-14]. Moreover, torque ripples and noises make them hard to be widely used in industry [14].

Machine model-based schemes use the instantaneous values of machine stator voltages and currents to estimate the speed and flux linkage. These methods utilize the direct and quadrature (d-q) axis mathematical models to describe the machine behavior by assuming sinusoidal flux distribution and neglecting harmonics [15]. Various methods based on machine model-based schemes have been introduced. The broadly known methods are open-loop speed estimator, sliding-mode observer (SMO) [12,16-19], adaptive full-order observer (AFO) [20-24], extended Kalman filter (EKF) [13,25-27], model reference adaptive system (MRAS) [28-31] and artificial neural network (ANN) based technique [32,33].

The open-loop speed estimation methods are simple to implement but they are sensitive to motor parameter variations, which lead to the estimation error. In [12,16-19], various SMO methods are presented. These methods are robust to the disturbances and easy to implement. However, they suffer from chattering problems [13] and unstable problems at low speed [14]. The higher order SMO [18,19] is proposed to reduce the chattering phenomenon while the formulation complexity is increased. A new adaptive SMO [12] is presented to improve the speed estimation at low speed but it has very complicated design. In [17], SMO based on magnetizing current estimation and a theorem for discrete time implementation are proposed.

AFO uses the stator current error for speed estimation and does not suffer from drifting problems. However, it requires much more effort on the design stage to select the parameters of the speed adaptation mechanism and design the feedback gain matrix. In [20], the simple and practical feedback gains design to ensure the stability of AFO is presented. The parameter sensitivity of AFO is discussed and a suitable feedback gains for AFO, which is robust to parameter variations, is introduced in [21]. In $[22,23]$, some novel designing rules to obtain satisfactory performances are proposed. The robustness of AFO to the motor parameter variations is also investigated, but the speed fluctuation becomes larger when speed decreased [13]. A speed estimation algorithm that considers the estimated rotor flux error and error coefficient is proposed in [24] to improve the robustness of AFO.

In [25], unscented Kalman filter (UKF) for IM sensorless drives is presented. EKF for stator flux and speed estimations in DTC is introduced [26], and the experimental results show that the system has satisfactory performances. EKF has strong robustness to the motor parameter variations and fast rate of convergence. Nevertheless, it requires exact knowledge of noise models and is much more 
complicated in practical realization $[13,14]$. The precise statistical characteristics of noises are very difficult to be achieved in the sensorless control system. To reduce the modeling errors, symmetric strong tracking extended Kalman filter (SSTEKF) [13] is introduced, but still has computational complexity. A two-stage Kalman filter is proposed in [27] to reduce the computational complexity of the classical EKF. Consequently, this method is more effective in implementation aspect.

MRAS concept is widely applied to speed estimation because of its simple structure, design simplicity, less computational effort and ease of practical implementation. It uses two models for speed estimation: reference model and adaptive model. The reference model does not depend on the speed while the adaptive model relies on it. The outputs of these models are compared and the differences are driven to zero by feeding into an adaptation mechanism, the output of which is the estimated speed. The adaptation mechanism based on Popov's criterion of hyperstability, Lyapunov stability method, and recursive least square (RLS) algorithm is used to minimize the difference between two models and assure the stability of the control system [28]. Several different speed estimators based on MRAS concept have been proposed [28]: rotor flux error based MRAS (rotor flux-MRAS) [29], back EMF error based MRAS (back EMF-MRAS) [29], reactive power error based MRAS (Q-MRAS) [29,30], X-MRAS [28,29] and stator current error based MRAS [31]. Although the rotor flux-MRAS is stable in wide speed range, the usage of pure integrator and dependence on the stator resistance in the reference model result in the speed estimation error at low speed. To avoid the problems in rotor flux-MRAS, back EMF-MRAS and Q-MRAS have been proposed. Back EMF-MRAS scheme does not use the pure integrator in the reference model but still depends on the stator resistance and may have stability problems at low speed. Q-MRAS technique offers robustness against stator resistance variation and avoids using the pure integrator. However, this method suffers from instability at some operating conditions. In [30], a new formulation of Q-MRAS, which solves the stability problems of the classical Q-MRAS, is proposed. X-MRAS shows the stability in low speed, but it is still dependent on the stator resistance. The stator current error based MRAS uses the measured stator current as the reference model. This makes the reference model free from using the pure integrator and independent to the motor parameter variations.

In [32], ANN incorporating with MRAS is proposed; the reference model uses offline trained ANN to replace the voltage model of rotor flux. The offline training leads to more time consumption and needs huge data for the input-output patterns for learning. The ANN adaptive model with online training is presented in [33], while the reference model uses the voltage model of rotor flux, which depends on stator resistance and uses pure integrator.

Recently, ANN has been widely used to identify and control nonlinear dynamic systems because it has the capability of wide range approximation of nonlinear functions to any desired degree of accuracy, fast optimization process and strong learning ability. The application of ANN for throttle valve control, which is a complex system and is perturbed by noise, is represented in [34]. This confirms the effectiveness of ANN. ANN can be trained by either offline or online learning [35]. In the offline training methods, they are slow and time consuming, and need huge data for the input-output patterns for learning. The main issues of using ANN for speed estimation are: it should have simple design, compact structure and less computational complexity to ensure that it requires short execution time for real time implementation. Hence, the online trained ANN is more suitable than the offline trained ANN for the speed estimation.

This paper presents an alternative speed estimator for speed sensorless DTC-CVFC of IM, using ANN. The estimated stator current equation is derived and rearranged consistent with the control algorithm and ANN structure, respectively. For the speed estimation, a weight in ANN, which relates to the speed, is adjusted by using Widrow-Hoff learning rule [36] to minimize the sum of squared errors between the measured stator current and the estimated stator current from the ANN output. The estimated speed is obtained by simple calculating from this weight. The consequence of using this method leads to the ability of online speed estimation and simple ANN structure. The enormous collected data and training phase, such as offline learning ANN, are not required, which results in the 
proposed speed estimator being suitable for real time implementation. Furthermore, the proposed method is similar to the stator current error based MRAS as the measured stator current is used as the reference model while the adaptive model is ANN and the adaptation mechanism utilizes Widrow-Hoff learning rule. The usage of the measured stator current as the reference model results in the reference model being independent from the motor parameter variations and the pure integrator is not required. The simulation and experimental results in high- and low-speed regions have confirmed the validity and effectiveness of the proposed speed estimation method.

The rest of this paper is organized as follows: Section 2 offers direct torque control based on constant $\mathrm{V} / \mathrm{F}$ control technique. Section 3 provides the proposed online artificial neural network speed estimator. The simulation and experimental results are represented in Section 4. Finally, the conclusions are given in Section 5 .

\section{Direct Torque Control Based on Constant Voltage per Frequency (V/F) Control Technique}

The basic concept of DTC-CVFC technique relies on the principles that the stator flux magnitude is directly proportional to the ratio between stator voltage magnitude and stator frequency (Equation (1)) and the torque depends on the stator voltage magnitude (Equation (2)) [37].

$$
\begin{gathered}
\left|\vec{\psi}_{s}\right| \approx\left|\vec{v}_{s}\right| / 2 \pi f \\
T_{e}=\frac{3}{2} \cdot \frac{P}{2} \cdot \frac{\left|\vec{v}_{S}\right|^{2}}{\pi f} \cdot \frac{R_{r} / S}{\left(R_{S}+R_{r} / S\right)^{2}+\left(X_{l s}+X_{l r}\right)^{2}}
\end{gathered}
$$

where $\left|\vec{\psi}_{s}\right|$ is the stator flux magnitude; $\left|\vec{v}_{s}\right|$ is the stator voltage magnitude; $P$ is the number of poles; $f$ is the motor frequency; $T_{e}$ is the electromagnetic torque; $R_{s}, R_{r}, X_{l s}$ and $X_{l r}$ are the stator and rotor resistance and leakage reactance, respectively; and $S$ is the slip.

To decouple control between the torque and stator flux, the stator flux magnitude will be controlled and regulated to be constant, this concept complies with the constant $\mathrm{V} / \mathrm{F}$ control principle, as shown in Equation (1). When considering Equation (2), under normal operation conditions, the slip is very small, implying that $R_{r} / S>>R_{S}$ and $R_{r} / S>>\left(X_{l s}+X_{l r}\right)$. Hence, the torque equation can be approximated as:

$$
T_{e} \approx \frac{3}{2} \cdot \frac{P}{2} \cdot \frac{\left|\vec{v}_{s}\right|^{2}}{\pi f} \cdot \frac{S}{R_{r}}
$$

Because the stator flux magnitude is forced to be constant as mentioned above and at each value of the speed in operation condition, the slip is constant. From Equation (3), it is found that torque is directly proportional to stator voltage magnitude, as shown in Equation (4),

$$
T_{e} \approx c \cdot\left|\vec{v}_{s}\right|
$$

where $c$ is a constant. In accordance with these concepts, the block diagram of DTC-CVFC for three-phase IM drives is shown in Figure 1. 


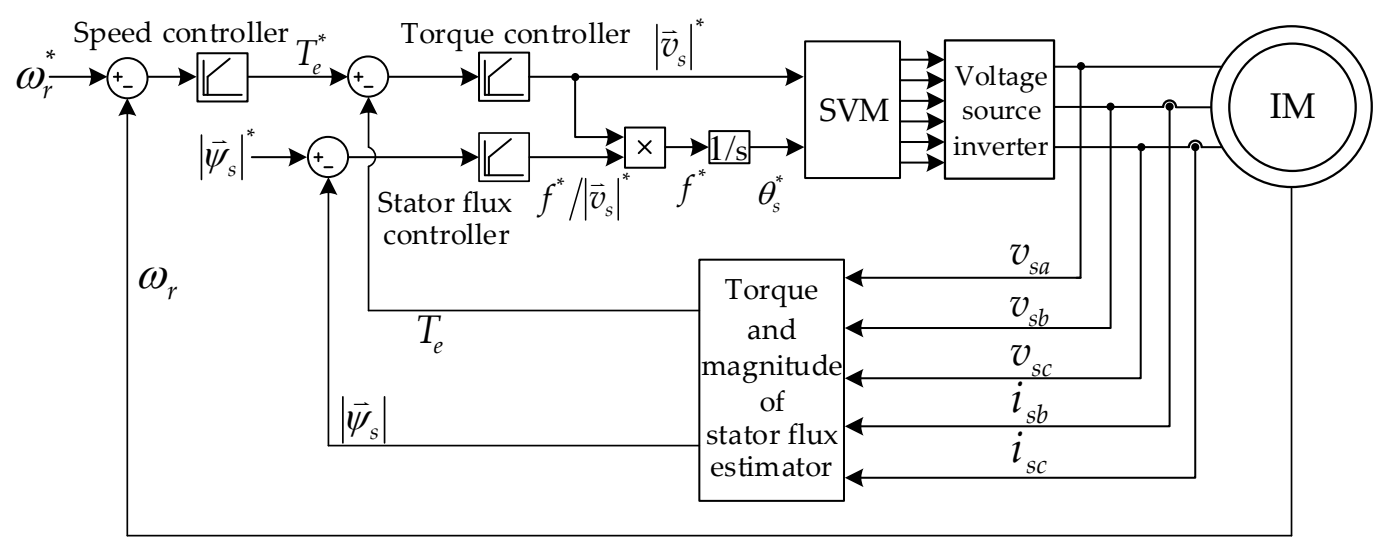

Figure 1. The block diagram of direct torque control based on constant voltage per frequency $(\mathrm{V} / \mathrm{F})$ control technique (DTC-CVFC) for three-phase induction motor (IM) drives. SVM: space vector modulation.

In Figure $1, \omega_{r}$ is the mechanical speed; $\theta_{s}$ is the stator phase angle; "**" stands for the reference value; and $v_{s a}, v_{s b}, v_{s c}, i_{s b}$ and $i_{s c}$ are the phase a, phase $\mathrm{b}$ and phase $\mathrm{c}$ stator voltage and stator current, respectively. PI controllers and SVM technique are utilized instead of the hysteresis comparators and look-up switching table of the conventional DTC. Furthermore, the coordinate transformation and current regulators are not used. The field-weakening operation is not considered in this paper. Hence, the stator flux magnitude reference is set as constant value. The torque and stator flux magnitude are calculated using Equations (5)-(8) [38].

$$
\begin{gathered}
T_{e}=\frac{3}{2} \cdot \frac{P}{2} \cdot\left(\psi_{s d} i_{s q}-\psi_{s q} i_{s d}\right) \\
\left|\vec{\psi}_{s}\right|=\sqrt{\psi_{s d}^{2}+\psi_{s q}^{2}} \\
\psi_{s d}=\int\left(v_{s d}-R_{s} i_{s d}\right) d t \\
\psi_{s q}=\int\left(v_{s q}-R_{s} i_{s q}\right) d t
\end{gathered}
$$

where $v_{s d}, v_{s q}, i_{s d}, i_{s q}, \psi_{s d}$ and $\psi_{s q}$ are d- and q- axis stator voltage components, stator current components and stator flux components, respectively. All quantities are expressed in stationary reference frame.

\section{Online Artificial Neural Network Speed Estimator}

The IM mathematical model in stationary reference frame under the assumption that magnetic circuit is linear, core losses are neglected, and magneto motive force (MMF) has sinusoidal distribution, is expressed as [38]:

$$
\left[\begin{array}{c}
v_{s d} \\
v_{s q} \\
0 \\
0
\end{array}\right]=\left[\begin{array}{cccc}
R_{s}+p L_{s} & 0 & p M & 0 \\
0 & R_{s}+p L_{s} & 0 & p M \\
p M & \omega M & R_{r}+p L_{r} & \omega L_{r} \\
-\omega M & p M & -\omega L_{r} & R_{r}+p L_{r}
\end{array}\right]\left[\begin{array}{c}
i_{s d} \\
i_{s q} \\
i_{r d} \\
i_{r q}
\end{array}\right]
$$

where $i_{r d}$ and $i_{r q}$ are $\mathrm{d}$ - and q- axis rotor current components, respectively, $\omega$ is the electrical speed, $M, L_{s}$ and $L_{r}$ are the mutual, stator and rotor inductances, respectively, and $p$ is the differential operator $d / d t$. 
To derive the estimated stator current consistent with DTC-CVFC technique, in which the stator flux is controlled variable, the stator flux equations that depend on stator and rotor currents are adopted as follows:

$$
\begin{aligned}
& \psi_{s d}=L_{s} i_{s d}+M i_{r d} \\
& \psi_{s q}=L_{s} i_{s q}+M i_{r q}
\end{aligned}
$$

By substituting Equations (10) and (11) into Equation (9), the estimated stator current equation can be written as:

$$
\frac{d}{d t}\left[\begin{array}{l}
\hat{i}_{s d} \\
\hat{i}_{s q}
\end{array}\right]=\left[\begin{array}{cccc}
-\frac{R_{s}^{*}}{\sigma L_{s}} & -\omega & \frac{R_{r}}{\sigma L_{s} L_{r}} & \frac{\omega}{\sigma L_{s}} \\
\omega & -\frac{R_{s}^{*}}{\sigma L_{s}} & -\frac{\omega}{\sigma L_{s}} & \frac{R_{r}}{\sigma L_{s} L_{r}}
\end{array}\right]\left[\begin{array}{l}
\hat{i}_{s d} \\
\hat{i}_{s q} \\
\hat{\psi}_{s d} \\
\hat{\psi}_{s q}
\end{array}\right]+\frac{1}{\sigma L_{s}}\left[\begin{array}{c}
v_{s d} \\
v_{s q}
\end{array}\right]
$$

where $R_{s}^{*}=R_{S}+L_{S} R_{r} / L_{r}, \sigma=1-M^{2} / L_{s} L_{r}$ and "^" denotes the estimated value. Applying forward rectangular rule [39] to Equation (12) and rearranging the result equation in accordance with ANN form that a weight of ANN must contain the speed, the discrete time estimated stator current is depicted in Equation (13):

$$
\left[\begin{array}{l}
\hat{i}_{s d}(k) \\
\hat{i}_{s q}(k)
\end{array}\right]=\left(1-\frac{T R_{s}^{*}}{\sigma L_{s}}\right)\left[\begin{array}{l}
\hat{i}_{s d}(k-1) \\
\hat{i}_{s q}(k-1)
\end{array}\right]+\frac{T \omega}{\sigma L_{s}} J\left[\begin{array}{l}
\hat{x}_{s d}(k-1) \\
\hat{x}_{s q}(k-1)
\end{array}\right]+\frac{T R_{r}}{\sigma L_{s} L_{r}}\left[\begin{array}{l}
\hat{\psi}_{s d}(k-1) \\
\hat{\psi}_{s q}(k-1)
\end{array}\right]+\frac{T}{\sigma L_{s}}\left[\begin{array}{c}
v_{s d}(k-1) \\
v_{s q}(k-1)
\end{array}\right]
$$

From Equation (13), the estimated stator current can be written in ANN form as:

$$
\overrightarrow{\vec{i}}_{s}(k)=w_{1} \vec{x}_{1}+w_{2} \vec{x}_{2}+w_{3} \vec{x}_{3}+w_{4} \vec{x}_{4}
$$

where $w_{1}=1-\frac{T R_{s}^{*}}{\sigma L_{s}}, w_{2}=\frac{T \omega}{\sigma L_{s}}, w_{3}=\frac{T R_{r}}{\sigma L_{s} L_{r}}, w_{4}=\frac{T}{\sigma L_{s}}, \vec{x}_{1}=\left[\begin{array}{c}\hat{i}_{s d}(k-1) \\ \hat{i}_{s q}(k-1)\end{array}\right], \vec{x}_{2}=J\left[\begin{array}{l}\hat{x}_{s d}(k-1) \\ \hat{x}_{s q}(k-1)\end{array}\right]$, $\vec{x}_{3}=\left[\begin{array}{l}\hat{\psi}_{s d}(k-1) \\ \hat{\psi}_{s q}(k-1)\end{array}\right], \vec{x}_{4}=\left[\begin{array}{c}v_{s d}(k-1) \\ v_{s q}(k-1)\end{array}\right], J=\left[\begin{array}{cc}0 & -1 \\ 1 & 0\end{array}\right], \hat{\vec{i}}_{s}(k)=\left[\begin{array}{l}\hat{i}_{s d}(k) \\ \hat{i}_{s q}(k)\end{array}\right], \hat{x}_{s d}(k)=$ $\sigma L_{s} \hat{i}_{s d}(k)-\hat{\psi}_{s d}(k), \hat{x}_{s q}(k)=\sigma L_{s} \hat{i}_{s q}(k)-\hat{\psi}_{s q}(k)$ and $T$ is the sampling period.

From Equation (14), ANN consists of two layers, input layer and output layer. Consequently, the suitable learning method for this ANN structure is Widrow-Hoff learning rule. Moreover, the weight update equation of this learning method is very simple so that Widrow-Hoff learning rule is more appropriate than other learning methods for online speed estimation [36]. Therefore, a weight, $w_{2}$, in Equation (14) that contains the speed will be adjusted online by Widrow-Hoff learning rule to minimize the sum of squared errors between the measured stator current and the estimated stator current. The sum of squared errors at sampling $k$ is defined by the energy function as:

$$
E=\frac{1}{2} \vec{e}^{T}(k) \vec{e}(k)
$$

where $\vec{e}(k)=\vec{i}_{s}(k)-\hat{\vec{i}}_{s}(k)=\left[i_{s d}(k)-\hat{i}_{s d}(k) i_{s q}(k)-\hat{i}_{s q}(k)\right]^{T}$.

To minimize the sum of squared error, Widrow-Hoff learning rule is used to adjust weight $w_{2}$ as:

$$
\Delta w_{2}=-\mu \frac{\partial E}{\partial w_{2}}=-\mu\left(\frac{\partial E}{\partial \hat{\vec{i}}_{s}(k)} \cdot \frac{\partial \vec{i}_{s}(k)}{\partial w_{2}}\right)=\mu \vec{e}^{T}(k) \vec{x}_{2}
$$

The updated weight can be written as:

$$
w_{2}(k)=w_{2}(k-1)+\Delta w_{2}
$$


By substituting Equation (16) and $w_{2}$ into Equation (17) and rearranging, the estimated speed can be written as:

$$
\hat{\omega}(k)=\hat{\omega}(k-1)+\eta \vec{e}^{T}(k) \vec{x}_{2}
$$

where $\mu$ is the positive value called as the learning rate, $(\cdot)^{T}$ means transpose and $\eta=\mu \sigma L_{s} / T$.

The block diagram of the proposed online ANN speed estimator is represented in Figure 2.

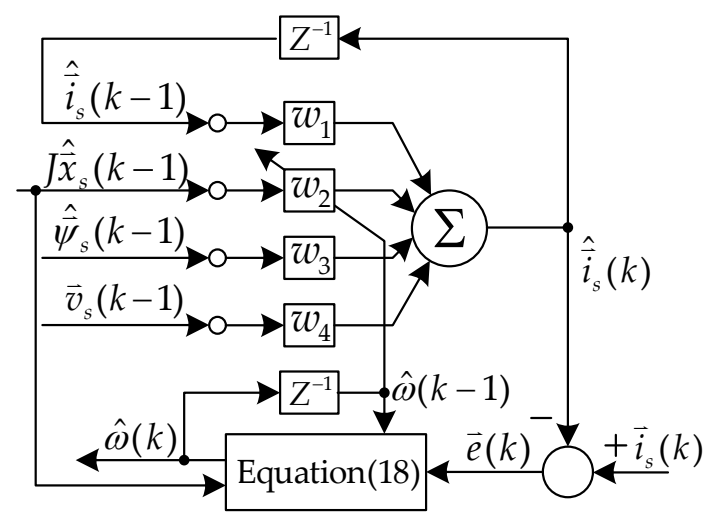

Figure 2. The block diagram of the proposed online artificial neural network (ANN) speed estimator.

$$
\begin{aligned}
& \text { In Figure } 2, \vec{i}_{s}(k)=\left[\begin{array}{l}
i_{s d}(k) \\
i_{s q}(k)
\end{array}\right], \vec{v}_{s}(k-1)=\left[\begin{array}{c}
v_{s d}(k-1) \\
v_{s q}(k-1)
\end{array}\right], \hat{\vec{x}}_{s}(k-1)=\left[\begin{array}{c}
\hat{x}_{s d}(k-1) \\
\hat{x}_{s q}(k-1)
\end{array}\right] \text { and } \\
& \vec{\psi}_{s}(k-1)=\left[\begin{array}{c}
\hat{\psi}_{s d}(k-1) \\
\hat{\psi}_{s q}(k-1)
\end{array}\right] .
\end{aligned}
$$

As shown in Figure 2, only the weight $w_{2}$ is adjusted online by Equation (18). Consequently, the convergence of the estimated stator current to the measured stator current strongly depends on the convergence of the estimated speed. The speed estimation in Equation (18) behaves as a low pass filter with the time constant that is inversely proportional with learning rate [40]. Hence, the estimation system will be stable if the positive learning rate is adopted. The small value of learning rate leads to the slow rate of the convergence while the large learning rate value brings to the fast convergence. However, it may cause the fluctuations in the estimated speed. To assure the stability, the learning rate should be selected carefully.

\section{Simulation and Experimental Results}

To validate the effectiveness, DTC-CVFC incorporated with the proposed online ANN speed estimator is simulated and experimented. The block diagram of the proposed speed sensorless control system is shown in Figure 3. The simulation is performed in Matlab/Simulink environment. The rule of thumb [41] is used to define the PI controller parameters for speed, stator flux magnitude and torque controllers. IM parameters and PI controller parameters are shown in Tables 1 and 2, respectively. To estimate speed online in accordance with Equation (18), only two parameters must be known that is the initial estimated speed and the learning rate $\mu$. The initial estimated speed and the learning rate are set equal 0 and $1 \times 10^{-5}$, respectively. These parameters are used in the simulations and experiments. For experiment, to avoid using the pure integrator, the modified integrator with an amplitude limiter [42] is adopted for the stator flux estimation because it is easy to implement, is suitable to the control method with constant flux magnitude control, does not require the speed information and can estimate the stator flux accurately in wide speed range. The cutoff frequency is $2 \mathrm{rad} / \mathrm{s}$ and limiter level is set equal to the stator flux magnitude reference that is $0.7 \mathrm{~Wb}$ for this stator flux estimator. 
Table 1. Parameters of a three-phase induction motor.

\begin{tabular}{llll}
\hline Voltage & $220 \mathrm{~V}$ Delta Connected & $R_{s}$ & $8.2 \Omega$ \\
Current & $3.5 \mathrm{~A}$ Delta Connected & $R_{r}$ & $8.62 \Omega$ \\
Power & $0.8 \mathrm{~kW}$ & $L_{s}$ & $700.79 \mathrm{mH}$ \\
Poles & 4 & $L_{r}$ & $700.79 \mathrm{mH}$ \\
Frequency & $50 \mathrm{~Hz}$ & $M$ & $644.87 \mathrm{mH}$ \\
Speed & $1400 \mathrm{rpm}$ & $J$ & $0.013 \mathrm{kgm}^{2}$ \\
Torque & $5.45 \mathrm{Nm}$ & Flux & $0.7 \mathrm{~Wb}$ \\
\hline
\end{tabular}

Table 2. Proportional-integral (PI) controller parameters.

\begin{tabular}{lcc}
\hline & $\boldsymbol{K}_{\boldsymbol{P}}$ & $\boldsymbol{K}_{\boldsymbol{I}}$ \\
\hline Speed & 500 & 20 \\
Torque & 200 & 5 \\
Stator flux magnitude & 800 & 20 \\
\hline
\end{tabular}

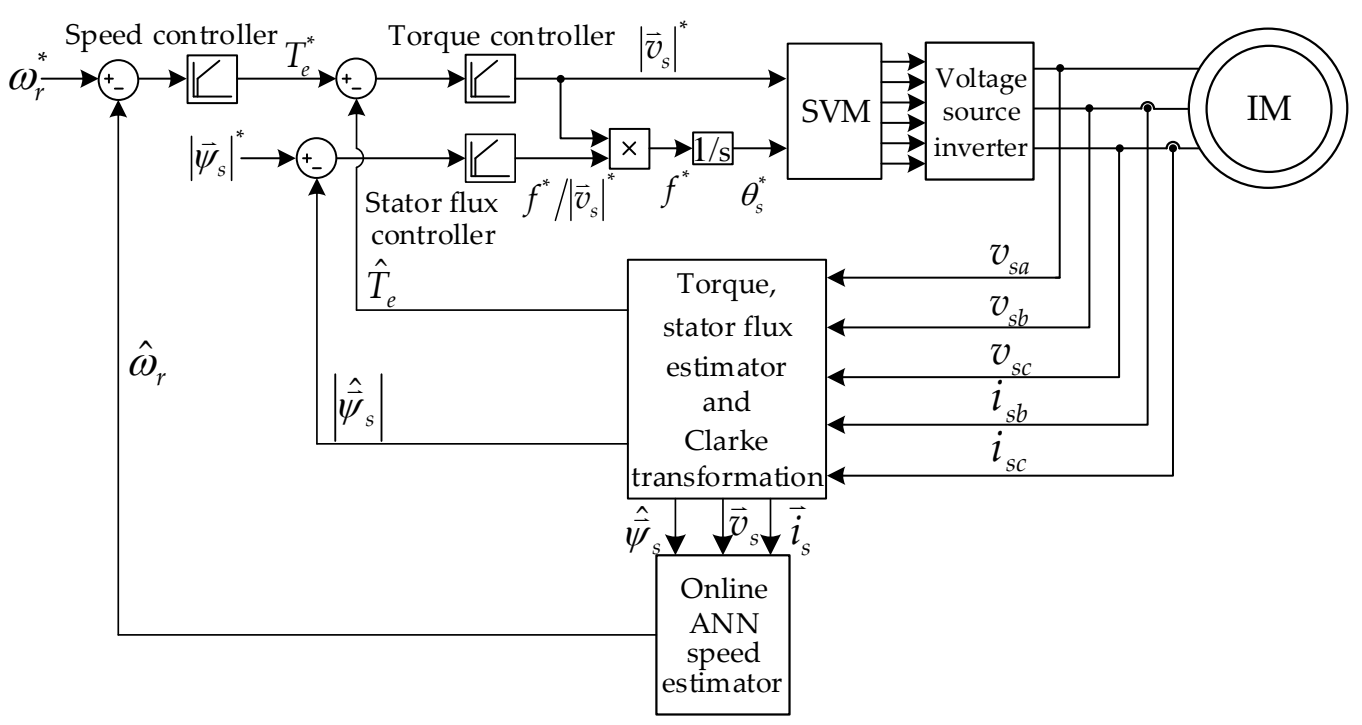

Figure 3. The block diagram of the proposed sensorless speed control system.

For simulation, the speed references are instantly changed from $0 \mathrm{rpm}$ (standstill) to $1400 \mathrm{rpm}$ (rated speed) for high speed operations and from standstill to $100 \mathrm{rpm}$ for low speed operations both at time $0.5 \mathrm{~s}$. The load torque is stepped from no load to full load $(5.45 \mathrm{Nm})$ at time $2 \mathrm{~s}$, then returns to no load again at time $4 \mathrm{~s}$ in each simulated situation.

The simulation results in high and low speed operations are shown in Figures 4 and 5, respectively. The online ANN speed estimator can estimate the speed correctly in both high and low speed ranges, as seen from the difference between the actual speed and the estimated speed $\left(\omega_{r}-\hat{\omega}_{r}\right)$ in Figures $4 \mathrm{~b}$ and $5 \mathrm{~b}$ for high speed and low speed, respectively. The maximum estimation error in high speed is around $2.5 \mathrm{rpm}$, with the same result for low speed. It can be concluded that the estimation errors are very small in transient operations and close to zero in steady-state operations. Speed, torque and stator flux magnitude are precisely controlled in steady-state conditions and has fast transient responses in both high- and low-speed regions, as shown in Figures $4 \mathrm{a}, \mathrm{c}, \mathrm{d}$ and $5 \mathrm{a}, \mathrm{c}, \mathrm{d}$, respectively. 


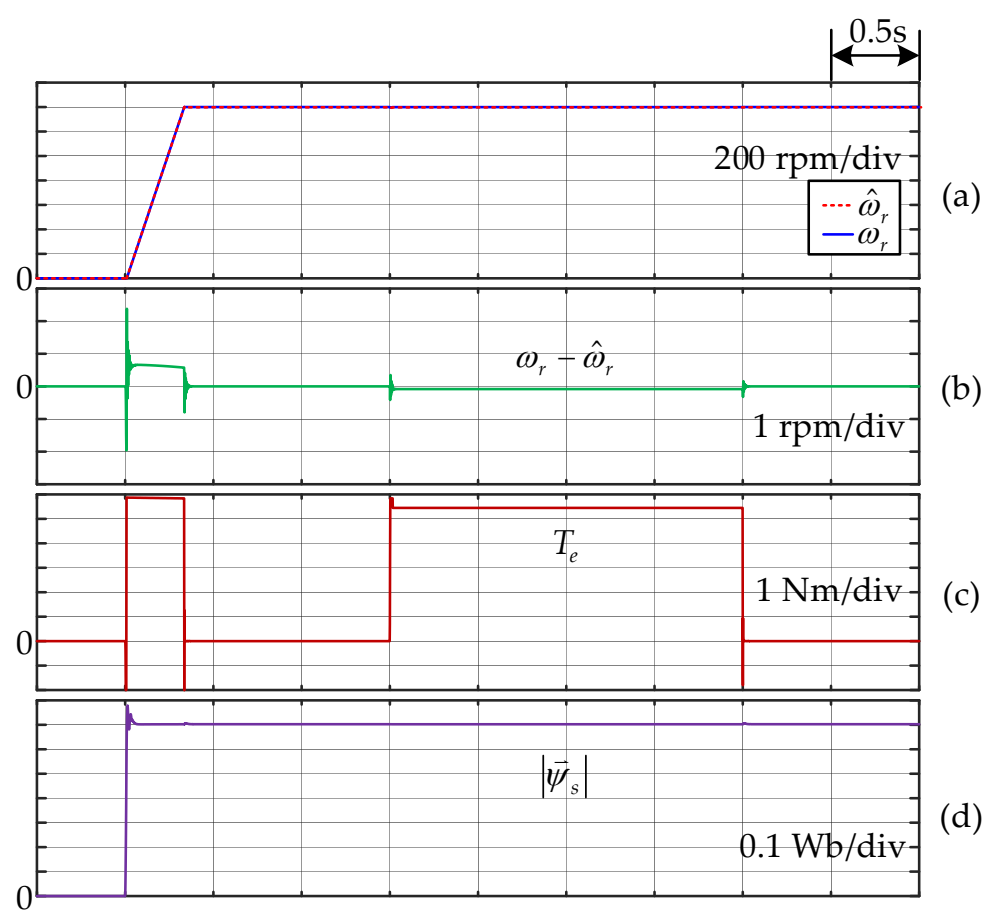

Figure 4. Simulation results when step speed from standstill to $1400 \mathrm{rpm}$ then $100 \%$ step-load change (a) actual speed response $\left(\omega_{r}\right)$ and estimated speed response $\left(\hat{\omega}_{r}\right),(\mathbf{b})$ estimation error, $(\mathbf{c})$ torque response, (d) stator flux magnitude response.

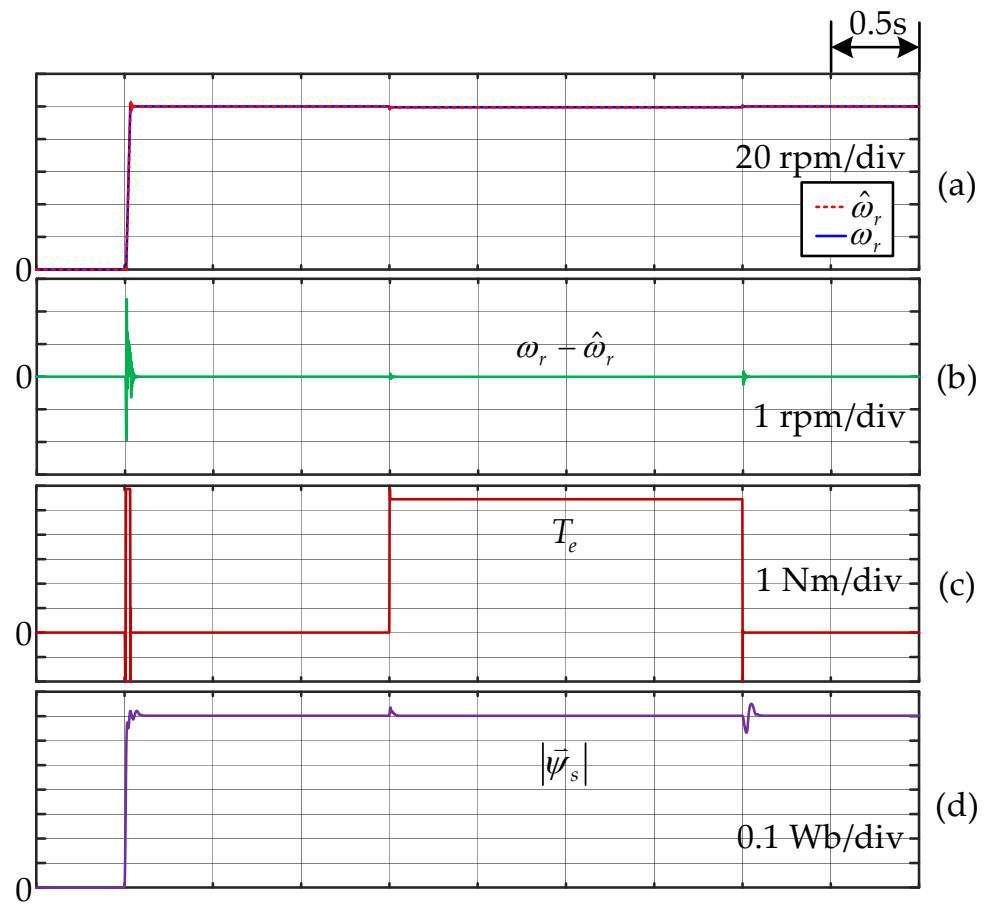

Figure 5. Simulation results when step speed from standstill to $100 \mathrm{rpm}$ then $100 \%$ step-load change (a) actual speed response $\left(\omega_{r}\right)$ and estimated speed response $\left(\hat{\omega}_{r}\right)$, (b) estimation error, (c) torque response, (d) stator flux magnitude response.

The experimental setup is displayed in Figure 6. A direct current (DC) generator with $1 \mathrm{~kW}, 220 \mathrm{~V}$, 5.2 A and $2000 \mathrm{rpm}$ connected to a resistor which is simulated as mechanical load for the tested motor. 
All algorithms for control, stator flux estimation and speed estimation are executed on DSP ADMC331. To ensure that it will have enough time for algorithm processing, data acquisition and conversion of analog to digital converter (ADC) and digital to analog converter (DAC), the sampling time is set equal $100 \mu \mathrm{s}$. The speed references are stepped from standstill to $1400 \mathrm{rpm}$ and standstill to $100 \mathrm{rpm}$ for high and low speed ranges testing, respectively. In each testing situation, the full load torque is applied when the speed response reaches the steady-state condition.

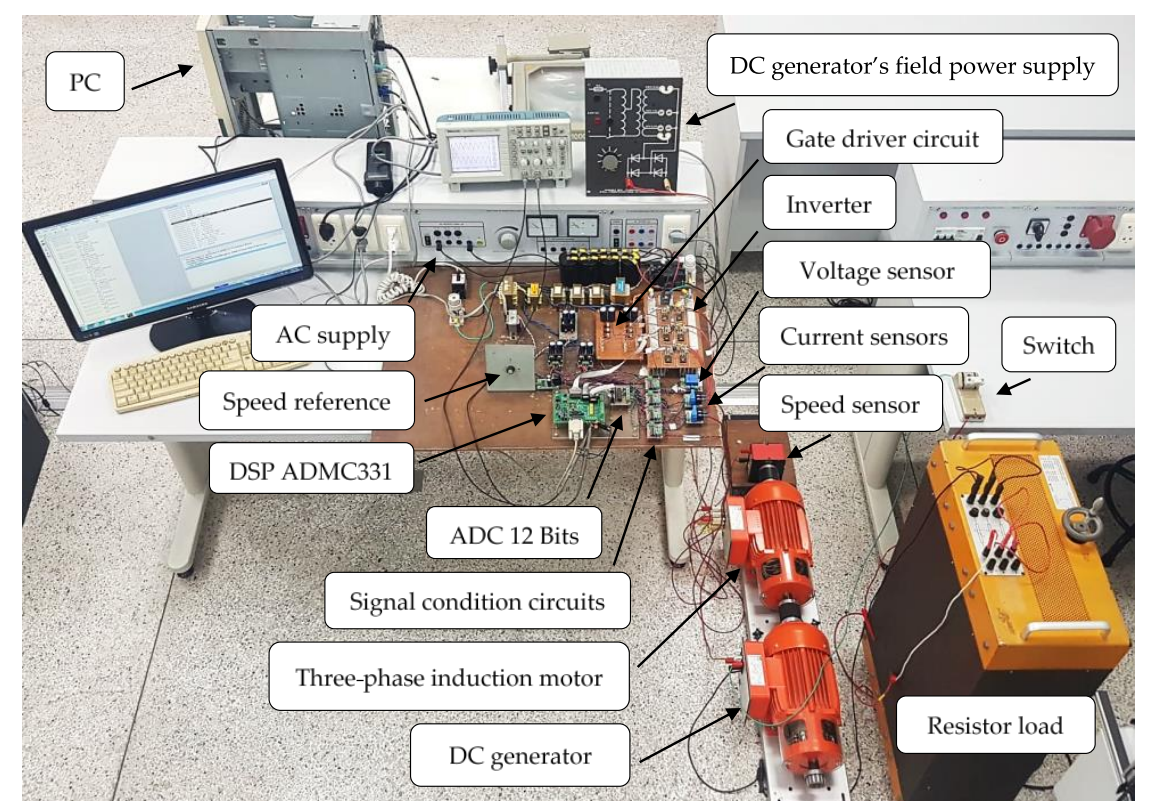

Figure 6. The experimental setup. PC: personal computer; AC: alternating current; ADC: analog to digital converter; DC: direct current.

Figures 7 and 8 demonstrate the experimental results in high and low speed operations, respectively. The proposed online ANN speed estimator can estimate the speed accurately when motor starting and during taking load, as shown in Figure $7 \mathrm{a}, \mathrm{b}$ and Figure $8 \mathrm{a}, \mathrm{b}$. The maximum estimation errors occur when motor starting with the value about $12 \mathrm{rpm}$ for high speed and $5 \mathrm{rpm}$ for low speed. Figure $7 \mathrm{c}, \mathrm{d}$ shows the stator flux trajectories when no load and full load of high speed operation. From these results, it is found that the controlled system is stable and the stator flux magnitude is controlled correctly. The same results can be observed in Figure $8 \mathrm{c}, \mathrm{d}$ for the low speed operation. The torque responses are very fast in both high and low speed operations as clearly shown in Figures $7 \mathrm{e}$ and $8 \mathrm{e}$. The validity and effectiveness of the proposed speed sensorless control system are confirmed by these results.

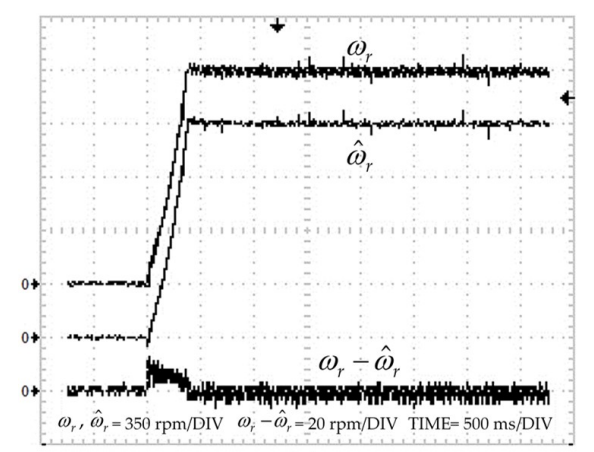

(a)

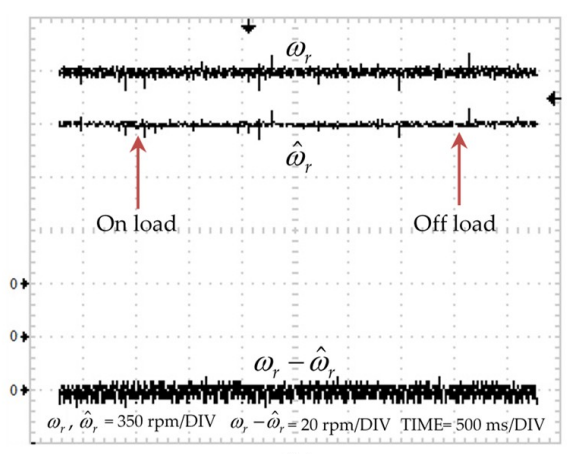

(b)

Figure 7. Cont. 


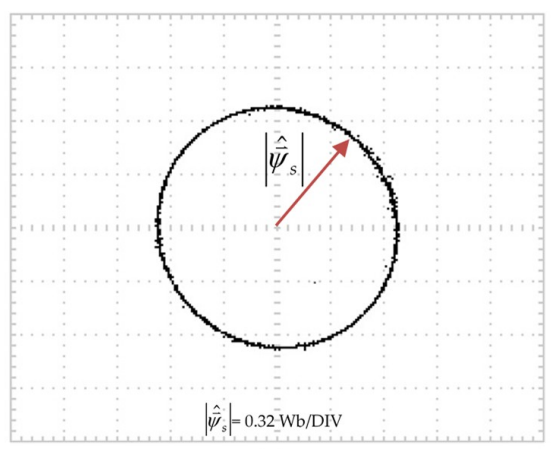

(c)

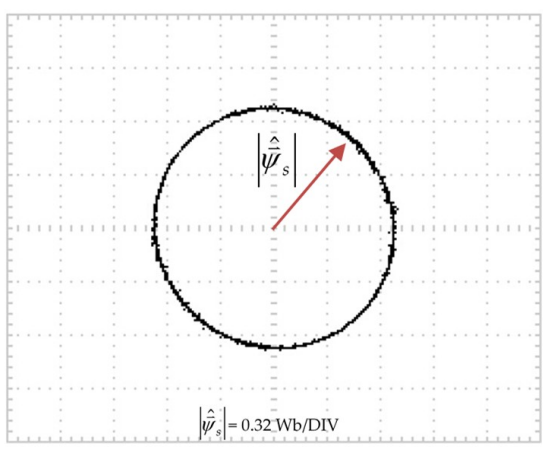

(d)

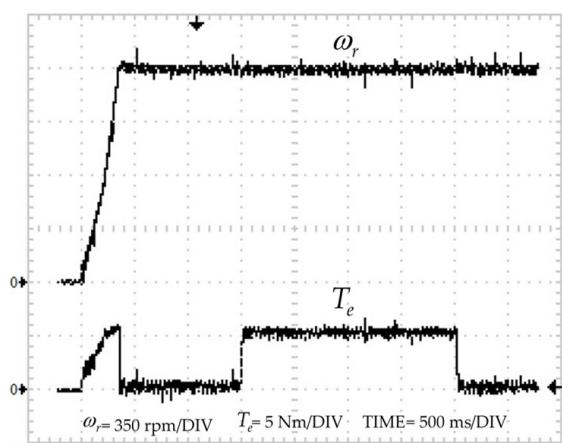

(e)

Figure 7. Experimental results when step speed from standstill to $1400 \mathrm{rpm}$ then $100 \%$ step-load change (a) actual speed response $\left(\omega_{r}\right)$, estimated speed response $\left(\hat{\omega}_{r}\right)$ and estimation error $\left(\omega_{r}-\hat{\omega}_{r}\right)$ when motor starting, (b) actual speed response $\left(\omega_{r}\right)$, estimated speed response $\left(\hat{\omega}_{r}\right)$ and estimation error $\left(\omega_{r}-\hat{\omega}_{r}\right)$ during taking load, (c) stator flux trajectory when no load, (d) stator flux trajectory when full load, (e) actual speed response $\left(\omega_{r}\right)$ and torque response $\left(T_{e}\right)$.

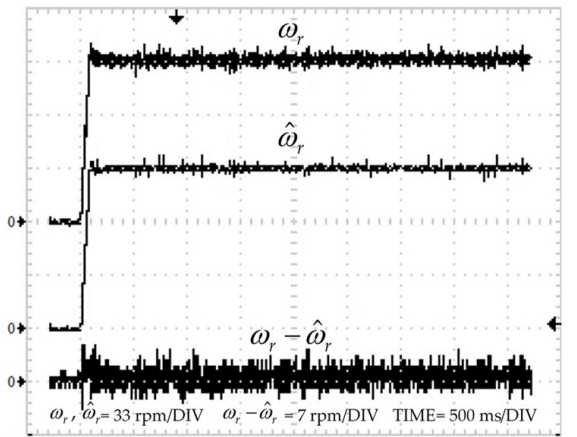

(a)

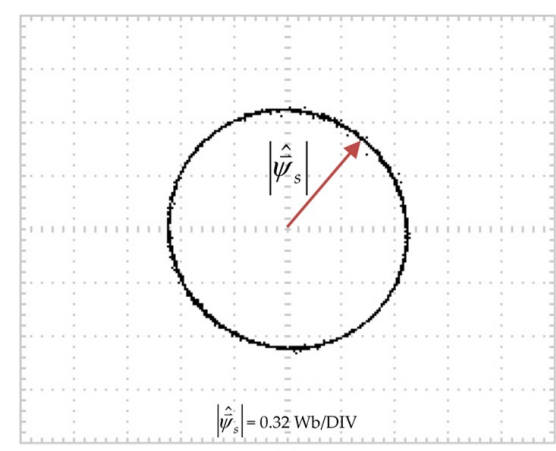

(c)

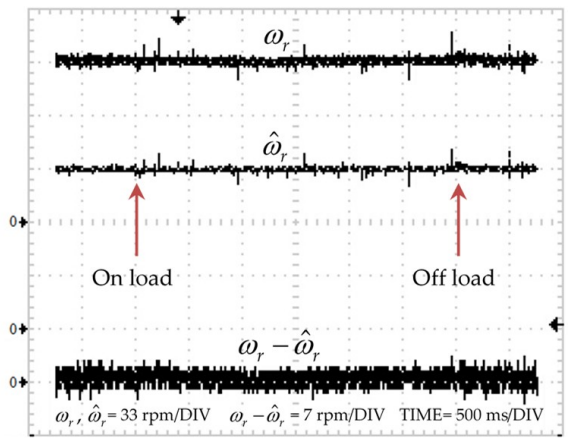

(b)

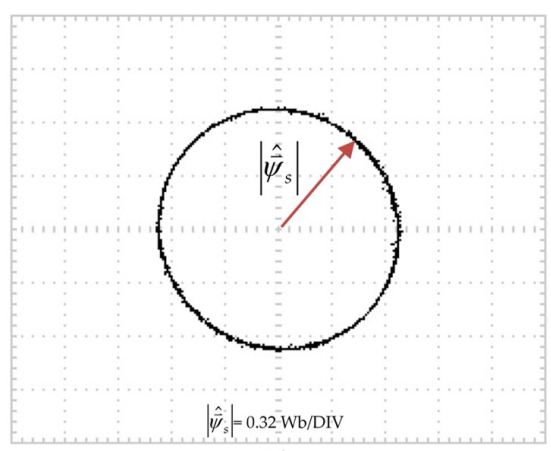

(d)

Figure 8. Cont. 


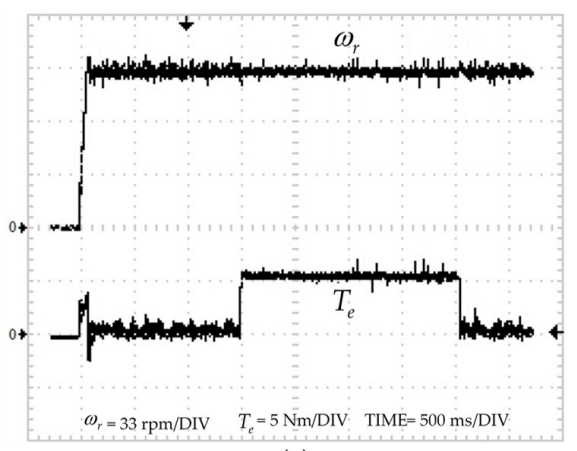

(e)

Figure 8. Experimental results when step speed from standstill to $100 \mathrm{rpm}$ then $100 \%$ step-load change (a) actual speed response $\left(\omega_{r}\right)$, estimated speed response $\left(\hat{\omega}_{r}\right)$ and estimation error $\left(\omega_{r}-\hat{\omega}_{r}\right)$ when motor starting, (b) actual speed response $\left(\omega_{r}\right)$, estimated speed response $\left(\hat{\omega}_{r}\right)$ and estimation error $\left(\omega_{r}-\hat{\omega}_{r}\right)$ during taking load, (c) stator flux trajectory when no load, (d) stator flux trajectory when full load, (e) actual speed response $\left(\omega_{r}\right)$ and torque response $\left(T_{e}\right)$.

\section{Conclusions}

An online ANN speed estimator for speed sensorless direct torque control of three-phase IM based on constant $\mathrm{V} / \mathrm{F}$ control technique is proposed in this paper. The simulation and experimental results show that this speed estimator can estimate speed accurately in both low- and high-speed regions. The control system when integrated to the offered speed estimator is stable, has fast dynamic responses and precise steady-state responses. These results confirm the effectiveness of the introduced online ANN speed estimator. However, in transient conditions, especially when motor starting, the estimation errors from experimental results are evidently different from the simulation results in both high- and low-speed regions, which may be the result of the parameter variations. The effect of the parameter variations will be considered and compensated in the future work.

Author Contributions: M.S.W. conceived and designed the experiments; N.P. performed the experiments; M.S.W. and N.P. analyzed the data; M.S.W. contributed materials and analytical tools; and N.P. and M.S.W. wrote the paper.

Funding: This research was funded by Ministry of Science and Technology, Taiwan, under contract No. of MOST 106-2221-E-218-002-.

Acknowledgments: The authors would like to thank Rajamangala University of Technology Lanna, Thailand, and Ministry of Science and Technology, Taiwan for financial supporting in publication this paper.

Conflicts of Interest: The authors declare no conflict of interest.

\section{References}

1. Kruselj, D. Methods for Direct Torque Control of Induction Machines. In Proceedings of the 2017 19th International Conference on Electrical Drives and Power Electronics (EDPE), Dubrovnik, Croatia, 4-6 October 2017; pp. 218-225.

2. Garg, R.; Mahajan, P.; Gupta, P.; Saroa, H. A Comparative Study between Field Oriented Control and Direct Torque Control of AC Traction Motor. In Proceedings of the International Conference on Recent Advances and Innovations in Engineering (ICRAIE-2014), Jaipur, India, 9-11 May 2014; pp. 1-6.

3. Parthan, A.; Suresh, L.P.; Raj, J.R.A. A Brief Review on Torque Control of Induction Motor. In Proceedings of the 2017 International Conference on Circuit, Power and Computing Technologies (ICCPCT), Kollam, India, 20-21 April 2017; pp. 1-5.

4. Kumar, T.V.; Rao, S.S. Direct Torque Control Method for Induction Motor Drives based on Modified Amplitude and Angle Decoupled Control of Stator Flux. In Proceedings of the 2010 Joint International Conference on Power Electronics, Drives and Energy Systems \& 2010 Power India, New Delhi, India, 20-23 December 2010; pp. 1-6. 
5. Zhang, Y.; Zhu, J.; Xu, W.; Guo, Y. A Simple Method to Reduce Torque Ripple in Direct Torque-Controlled Permanent-Magnet Synchronous Motor by Using Vectors with Variable Amplitude and Angle. IEEE Trans. Ind. Electron. 2010, 58, 2848-2859. [CrossRef]

6. Pimkumwong, N.; Onkrong, A.; Sapaklom, T. Modeling and Simulation of Direct Torque Control Induction Motor Drives via Constant Volt/Hertz Technique. Procedia Eng. 2012, 31, 1211-1216. [CrossRef]

7. Pimkumwong, N.; Wang, M.S. Full-Order Observer for Direct Torque Control of Induction Motor based on Constant V/F Control Technique. ISA Trans. 2018, 73, 189-200. [CrossRef] [PubMed]

8. Suwankawin, S.; Srivorakul, A. A Syncho-Perspective-Based High-Frequency Voltage Injection Method for Position-Sensorless Vector Control of Doubly Fed Induction Machines. IEEE Trans. Ind. Appl. 2018, 54, 3326-3337.

9. Pacas, M. Sensorless Drives in Industrial Applications. IEEE Ind. Electron. Mag. 2011, 5, 16-23. [CrossRef]

10. Xu, L.; Inoa, E.; Liu, Y.; Guan, B. A New High-Frequency Injection Method for Sensorless Control of Doubly Fed Induction Machines. IEEE Trans. Ind. Appl. 2012, 48, 1556-1564. [CrossRef]

11. Jung, S.H.; Doki, S.; Okuma, S.; Fujitsuna, M. Sensorless Control Method with Relatively Low Frequency Signal Injection for Low Acoustic Noise. In Proceedings of the 2011 14th European Conference on Power Electronics and Applications, Birmingham, UK, 30 August-1 September 2011; pp. 1-7.

12. Zaky, M.S.; Metwaly, M.K.; Azazi, H.Z.; Deraz, S.A. A New Adaptive SMO for Speed Estimation of Sensorless Induction Motor Drives at Zero and Very Low Frequencies. IEEE Trans. Ind. Electron. 2018, 65, 6901-6911. [CrossRef]

13. Yin, Z.; Li, G.; Zhang, Y.; Liu, J. Symmetric-Strong-Tracking-Extended-Kalman-Filter-Based Sensorless Control of Induction Motor Drives for Modeling Error Reduction. IEEE Trans. Ind. Inform. 2018. [CrossRef]

14. Xu, D.; Wang, B.; Zhang, G.; Wang, G.; Yu, Y. A Review of Sensorless Control Methods for AC Motor Drives. CES Trans. Electr. Mach. Syst. 2018, 2, 104-115.

15. Finch, J.W.; Giaouris, D. Controlled AC Electrical Drives. IEEE Trans. Ind. Electron. 2008, 55, 481-491. [CrossRef]

16. Lascu, C.; Boldea, I.; Blaabjerg, F. A Class of Speed-Sensorless Sliding-Mode Observer for High-Performance Induction Motor Drives. IEEE Trans. Ind. Electron. 2009, 56, 3394-3403. [CrossRef]

17. Vieira, R.P.; Gastaldini, C.C.; Azzolin, R.Z.; Grundling, H.A. Sensorless Sliding-Mode Rotor Speed Observer of Induction Machines Based on Magnetizing Current Estimation. IEEE Trans. Ind. Electron. 2014, 61, 4573-4582. [CrossRef]

18. Zhao, L.; Huang, J.; Liu, H.; Li, B.; Kong, W. Second-Order Sliding-Mode Observer with Online Parameter Identification for Sensorless Induction Motor Drives. IEEE Trans. Ind. Electron. 2014, 61, 5280-5289. [CrossRef]

19. Gennaro, S.D.; Dominguez, J.R.; Meza, M.A. Sensorless High Order Sliding Mode Control of Induction Motors with Core Loss. IEEE Trans. Ind. Electron. 2014, 61, 2678-2689. [CrossRef]

20. Rattanaudompisut, A.; Po-ngam, S. The Practical and Simple Feedback Gains Design of an Adaptive Full-Order Observer for Speed-Sensorless Induction Motor Drives. In Proceedings of the 2015 12th International Conference on Electrical Engineering/Electronics, Computer, Telecommunications and Information Technology (ECTI-CON), Hua Hin, Thailand, 24-27 June 2015; pp. 1-6.

21. Chen, B.; Yao, W.; Chen, F.; Lu, Z. Parameter Sensitivity in Sensorless Induction Motor Drives with the Adaptive Full-Order Observer. IEEE Trans. Ind. Electron. 2015, 62, 4307-4318. [CrossRef]

22. Sun, W.; Yu, Y.; Wang, G.; Li, B.; Xu, D. Design Method of Adaptive Full Order Observer with or without Estimated Flux Error in Speed Estimation Algorithm. IEEE Trans. Power Electron. 2016, 31, 2609-2626. [CrossRef]

23. Po-ngam, S.; Sangwongwanich, S. Stability and Dynamic Performance Improvement of Adaptive Full-Order Observer for Sensorless PMSM Drive. IEEE Trans. Power Electron. 2012, 27, 588-600. [CrossRef]

24. Sun, W.; Gao, J.; Yu, Y.; Wang, G.; Xu, D. Robustness Improvement of Speed Estimation in Speed-Sensorless Induction Motor Drives. IEEE Trans. Ind. Electron. 2016, 52, 2525-2536. [CrossRef]

25. Jafarzadeh, S.; Lascu, C.; Fadali, M.S. State Estimation of Induction Motor Drives Using the Unscented Kalman Filters. IEEE Trans. Ind. Electron. 2012, 59, 4207-4216. [CrossRef]

26. Alsofyani, I.M.; Idris, N.R.N. Simple Flux Regulation for Improving State Estimation at Very Low and Zero Speed of a Speed Sensorless Direct Torque Control of an Induction Motor. IEEE Trans. Power Electron. 2016, 31, 3027-3035. [CrossRef] 
27. Hilairet, M.; Auger, F.; Berthelot, E. Speed and Rotor Flux Estimation of Induction Machines Using a Two-Stage Extended Kalman Filter. Autometica 2009, 45, 1819-1827. [CrossRef]

28. Kumar, R.; Das, S.; Syam, P.; Chattopadhyay, A.K. Review on Model Reference Adaptive System for Sensorless Vector Control of Induction Motor Drives. IET Electr. Power Appl. 2015, 9, 496-511. [CrossRef]

29. Verma, V.; Chakraborty, C. New Series of MRAS for Speed Estimation of Vector Controlled Induction Motor Drive. In Proceedings of the IECON 2014-40th Annual Conference of the IEEE Industrial Electronics Society, Dallas, TX, USA, 29 October-1 November 2014; pp. 755-761.

30. Teja, A.V.R.; Verma, V.; Chakraborty, C. A New Formulation of Reactive-Power-Based Model Reference Adaptive System for Sensorless Induction Motor Drive. IEEE Trans. Ind. Electron. 2015, 62, 6797-6808. [CrossRef]

31. Orlowska-Kowalska, T.; Dybkowski, M. Stator-Current-Based MRAS Estimator for a Wide Range Speed-Sensorless Induction-Motor Drive. IEEE Trans. Ind. Electron. 2010, 57, 1296-1308. [CrossRef]

32. Yang, Y. A Neural Network Model Reference Adaptive System for Speed Estimation of Sensorless Induction Motor. In Proceedings of the 2017 29th Chinese Control and Decision Conference (CCDC), Chongqing, China, 28-30 May 2017; pp. 6864-6868.

33. Nguyen, S.T.; Pham, P.H.; Pham, T.V.; Ha, H.X.; Nguyen, C.T.; Do, P.C. A Sensorless Three-Phase Induction Motor Drive Using Indirect Field Oriented Control and Artificial Neural Network. In Proceedings of the 2017 12th IEEE Conference on Industrial Electronics and Applications (ICIEA), Siem Reap, Combodia, 18-20 June 2017; pp. 1454-1459.

34. Nentwig, M.; Mercorelli, P. Throttle Valve Control Using an Inverse Local Linear Model Tree Based on a Fuzzy Neural Network. In Proceedings of the 2008 7th IEEE International Conference on Cybernetic Intelligent Systems, London, UK, 9-10 September 2008; pp. 1-6.

35. Sedhuraman, K.; Himavathi, S.; Muthuramalingam, A. Comparison of Learning Algorithms for Neural Network Based Speed Estimation in Sensorless Induction Motor Drives. In Proceedings of the IEEE-International Conference on Advances in Engineering, Science and Management (ICAESM-2012), Nagapattinam, Tamil Nadu, India, 30-31 March 2012; pp. 196-202.

36. Kartalopoulos, S.V. Understanding Neural Networks and Fuzzy Logic: Basic Concepts and Applications, 1st ed.; IEEE Press: Piscataway, NJ, USA, 1995; pp. 46-73.

37. Trzynadlowski, A.M. Control of Induction Motors, 1st ed.; Academic Press: San Diego, CA, USA, 2001; pp. 29-98.

38. Vas, P. Sensorless Vector and Direct Torque Control, 1st ed.; Oxford University Press: New York, NY, USA, 1998; pp. 39-422.

39. Franklin, G.F.; Powell, J.D.; Workman, M. Digital Control of Dynamic System, 3rd ed.; Addison Wesley Longman, Inc.: Redwood City, CA, USA, 1997; pp. 189-195.

40. Haykin, S. Neural Networks: A Comprehensive Foundation, 2nd ed.; Prentice Hall International, Inc.: Upper Saddle River, NJ, USA, 1999; pp. 128-133.

41. Ellis, G. Control System Design Guide, 2nd ed.; Academic Press: San Diego, CA, USA, 2000; pp. 105-106.

42. $\mathrm{Hu}, \mathrm{J} . ; \mathrm{Wu}, \mathrm{B}$. New Integration Algorithms for Estimating Motor Flux over a Wide Speed Range. IEEE Trans. Power Electron. 1998, 13, 969-977.

(C) 2018 by the authors. Licensee MDPI, Basel, Switzerland. This article is an open access article distributed under the terms and conditions of the Creative Commons Attribution (CC BY) license (http:// creativecommons.org/licenses/by/4.0/). 